DOI: $10.31249 / \mathrm{rsm} / 2018.03 .09$

\title{
Б.А. Сереков
}

\section{КИТАЙСКИЙ ПРОЕКТ “ОАИН ПОЯС - ОАИН ПУТЬ": ПРОБАЕМЫ И ПЕРСПЕКТИВЫ РЕААИЗАЦИИ}

Аннотация. В статье анализируется система отношений между Европейским союзом, Евразийским экономическим союзом и Китаем в свете реализации китайского проекта «Один пояс - один путь». Описаны перспективы его реализации, связанные с ним сложности и риски для Западной Европы и России.

Ключевые слова: Европейский союз, Евразийский экономический союз, стратегия «Один пояс - один путь», экономические отношения, Китай, Западная Европа, Россия, ЕАЭС.

Сереков Бауыржан Алиакбарович - аспирант

Российской академии народного хозяйства

и государственной службы при Президенте РФ, Москва.

Email: bas.01@inbox.ru

B.A. Serekov. Chinese One Belt, One Way Strategy: Problems and Perspectives of Implementation

Abstract. The article adresses the current relationships between the European Union, Eurasian Economic Union and the Chinese One belt, One way strategy. Showing the dynamics of the Chinese initiative towards Europe, the author underlines the asymmetry between the sides of the «triangle» and describes prospects and risks inherent in the synergy of the three projects.

Keywords: The European Union, the Eurasian Economic Union, the One belt, One way strategy, economic relations, China, Western Europe, Russia, EAEC.

Serekov Baurzhan Aliakbarovich - postgraduate student

of the Russian Presidential Academy

of National Economy and Public Administration,

Moscow. Email: bas.01@inbox.ru 
Сегодня на пространстве Большой Евразии, к которой относят и Западную Европу, сформировались в различной степени зрелости три интеграционных мегапроекта - к Европейскому союзу и Евразийскому экономическому союзу добавился «Один пояс - один путь», энергично продвигаемый Китаем ${ }^{1}$. В связи с этим специалисты обсуждают множество вопросов: возможно ли сопряжение этих трех проектов; если возможно, то какие сложности и препятствия могут возникнуть на этом пути; каковы перспективы «треугольника», исторически беспрецедентного по своим масштабам и, возможно, экономическому и геополитическому значению в будущем?

Анализ всего этого круга вопросов сегодня представляет собой сложнейшую научную задачу. ЕС - самый большой в мире экономический блок, ЕАЭС охватывает самую большую в мире территорию, а «Один пояс - один путь» - наибольшую долю населения мира, свыше $60 \%$ мирового населения (вместе с Китаем и теми государствами, которые уже официально заявили о своем намерении участвовать в проекте). В географическом плане объединения пересекаются друг с другом, и это образует ситуацию, которая в прошлом всегда порождала межгосударственное и межблоковое соперничество, конфликты и войны. Могут ли сегодня мотивы и цели сторон совпасть?

В долгосрочном плане ответа на этот вопрос, естественно, нет. Для перспективы более или менее близкой можно с осторожностью говорить, что сближение трех интеграционных объединений, которое так или иначе уже началось, скорее всего, будет продолжаться. Процесс, однако, не лишен противоречий и серьезных факторов неопределенности.

Вся конструкция «треугольника» асимметрична. ЕС обладает широко разветвленной институциональной структурой, ЕАЭС также достаточно далеко продвинулся на пути институциализации механизмов и направлений регионального сотрудничества, институциализация китайского проекта на сегодняшний день практически отсутствует. ЕС - самый большой общий рынок мира с совокупным ВВП порядка 15 трлн евро, Китай - вторая экономика мира; показатели экономики России и ее партнеров по Евразийскому союзу много скромнее - здесь совокупный ВВП пяти государств-участников в 2016 г. находился на отметке ниже 4,5 трлн долл. ЕС даже при всех своих противоречиях последних лет представляет собой внутренне довольно солидарное объединение 27 государств, вопрос о внутреннем единстве ЕАЭС, особенно при перспективе вступления в Союз новых членов, пока достаточно

1. Напомним читателю, что в данном случае понятие «пояс» относится к китайской инициативе «Экономический пояс Шёлкового пути», а «путь» - к другой инициативе КНР, получивщей название «Морского шёлкового пути ХХІ века». Обе инициативы были заявлены в 2013 г. и вместе несут в себе идею возрождения торговых маршрутов исторического Шёлкового пути. 


\section{РОССИЯ И МИР В ХХІ ВЕКЕ}

проблематичен, «Один пояс - один путь» предполагает взаимодействие от 60 до 100 государств, которые выступать с единых позиций, естественно, не могут. Наконец, в «треугольнике» за последнее время явственно обозначилось слабое звено - кризисная ситуация в отношениях между Россией и ЕС, тогда как уровень экономических отношений в парах ЕС - Китай и ЕАЭС - Китай постоянно повышается.

Очевидно, что перспективы становления новых глобальных магистралей следует рассматривать пошагово и по отдельным «строительным участкам», отделяя факты и процессы, уже имеющие место, от предположений.

Прежде всего не подлежит сомнению то, что китайское руководство не только не откажется от идеи строительства новых транспортных коридоров, но и будет наращивать усилия в этом направлении. Мотивы Пекина в этом случае многообразны. С падением темпов экономического роста страна крайне нуждается в выходе на новые рынки. Как одна из ведущих торговых держав мира Поднебесная в принципе заинтересована в сокращении транспортных издержек экспорта и импорта, и именно такую перспективу обещают новые транспортные пути в Азии и Европе. В китайской экономике накопились избыточные производственные мощности, особенно в тяжелом машиностроении, производстве потребительских товаров, цемента, стали и других металлов. Новые рынки сбыта и, главное, строительство новых железнодорожных путей могли бы снять эту проблему избыточности. Пекин ожидает, что национальные компании будут осуществлять планирование, исполнение и последующее обеспечение соответствующих проектов вдоль нового Шёлкового пути, именно на таких условиях и кредитуя своих зарубежных партнеров. Растут энергетические потребности страны и, следовательно, ее заинтересованность в импорте энергоносителей из стран Центральной Азии и России (по газопроводам), а также из Юго-Восточной Азии (через глубоководные порты). Банковский сектор Китая стремится найти новые объекты для инвестиций, а инфраструктурные проекты в этом смысле обещают в перспективе более высокие доходы, чем дают вложения в малодоходные ценные бумаги США. Финансируя зарубежные проекты, где кредиты предоставляются в юанях, Китай укрепляет статус юаня как мировой резервной валюты. В действиях Пекина просматривается и такой мотив, как стремление развивать свои относительно отсталые регионы на западе страны. Наконец, расширяя сотрудничество со странами Центральной Азии, КНР, наряду с другими своими целями, стремится создать для себя более стабильную международную среду с тем, чтобы смягчить остроту проблем, связанных с уйгурским меньшинством. За проектом «Один пояс - один путь», таким образом, стоит сложная комбинация экономических, геоэкономических и геополитических интересов КНР. 
Для осуществления данной стратегии Пекин мобилизует огромные ресурсы. Председатель КНР Си Цзиньпин, выступая на Международном экономическом форуме «Один пояс - один путь» (май 2017 г.), отметил, что на поддержку инфраструктурных проектов в более чем 60 странах Пекин в среднесрочной перспективе предполагает направить свыше 1 трлн долл. Эксперты, пытаясь определить общую стоимость проекта (в более или менее отдаленной перспективе), указывают на цифры в диапазоне от 4 до 8 трлн долл. [10]. В аналитических СМИ при этом отмечается, что «с концепцией Нового Шёлкового пути связано огромное количество цифр. Никто точно не знает, какова сумма уже подписанных соглашений в рамках наземного и морского торговых путей, но называется сумма в 300 млрд долл. Большинство этих проектов будет развиваться в следующем десятилетии. Рейтинговое агентство Fitch оценивает вложения в запланированные или уже осуществляемые проекты в 900 млрд долл. Распространено мнение, что на развитие концепции к 2022 г. будет потрачено 5 трлн долл. Специалисты Азиатского банка развития считают, что к 2030 г. в инфраструктурные проекты будут вложены невероятные 26 трлн долл.» [4].

Итак, какими бы темпами ни развивались отдельные проекты в рамках «Один пояс - один путь», очевидно, что Пекин будет упорно продвигать свою региональную и глобальную интеграционную стратегию, и это так или иначе отразится на отношениях Китая с другими интеграционными блоками. Как это может отразиться на его отношениях с объединенной Европой?

\section{ЕС и Китай на пути \\ К "зрелому" партнерству}

Отправной точкой анализа сегодняшних отношений между ЕС и Китаем, на наш взгляд, должен быть тот факт, что между сторонами уже давно развивается «всеобъемлющее стратегическое партнерство», официально декларированное в 2003 г. и с тех пор постоянно расширяющее все новые и новые области сотрудничества. В 2013 г. в рамках этого партнерства была принята «Стратегическая повестка сотрудничества между ЕС и Китаем до 2020 г. (EU - China 2020 Strategic Agenda for Cooperation), наметившая задачи в четырех широких областях, обозначенных как «мир», «процветание», «устойчивое развитие» и «человеческие контакты». Несколько государств ЕС в 2015 г. вошли в состав участников Азиатского банка инфраструктурных инвестиций, сегодня обслуживающего проекты в рамках «Один пояс - один путь», а Китай в 2016 г. вошел в число акционеров Европейского банка реконструкции и развития. В том же году была подписана дорожная карта по сотрудничеству в энергетическом секторе, имеющая в виду развитие проектов по низкоуглеродной энергетике, ядерной и возобновляемой энергии. 
В июне 2017 г., после того как США объявили о своем выходе из Парижского соглашения по климату, ЕС и Китай в порядке дальнейшей институциализации механизмов своего сотрудничества наметили ряд совместных мер по борьбе с глобальным потеплением.

Ядром отношений сторон является, конечно, торговля. Сегодня ЕС для Китая - первый по значимости торговый партнер, а Китай для ЕС - второй после США. С 2006 по 2016 г. экспорт стран ЕС в Китай утроился и достиг цифры 170 млрд долл. в год, а импорт из Китая достиг еще более высокого уровня - 345 млрд долл. в год [7]. Развитый рынок объединенной Европы с ее полумиллиардным населением, возможно, главный целевой ориентир глобальной торговой стратегии Пекина. Не случайно сухопутный и морской компоненты Нового Шёлкового пути сходятся именно в Западной Европе. Со своей стороны экономики ЕС, особенно после кризиса 2008-2009 гг., крайне заинтересованы в китайских инвестициях, ежегодный уровень которых сегодня превышает 35 млрд евро. Как подчеркивается в прессе, «в последнее время ЕС и его государства-члены все в большей степени замыкаются внутри Союза. В этой ситуации ЕС отчаянно нуждается в поддержке Китая и в сотрудничестве с ним, особенно в вопросах торговли и инвестиций» [13].

Все более важное место во взаимоотношениях сторон занимают вопросы научного, технологического и инновационного сотрудничества. Весной 2017 г. приоритеты в этом направлении были официально сформулированы в Соглашении о научном и технологическом сотрудничестве между ЕС и Китаем, где стороны обозначили такие «флагманские» темы для совместных разработок, как продовольствие, сельское хозяйство, окружающая среда и устойчивая урбанизация, наземный транспорт, авиация и биотехнологии [9]. Как в ЕС, так и в Китае инновациям сегодня придается исключительно важное значение. В ЕС обширная стратегия «Европа-2020» предполагает движение к так называемому Инновационному союзу, в связи с чем особое внимание уделяется вопросам изменения климата, рационального использования энергии и ресурсов, здравоохранения и демографии. В КНР очередной пятилетний план (2016-2020) выдвинул задачу интеграции страны в мировые инновационные сети как одну из ключевых стратегий радикальной перестройки китайской экономики. В 2015 г. здесь был принят первый в истории страны десятилетний план действий «Сделано в Китае - 2025», нацеленный на радикальную модернизацию обрабатывающей промышленности, продвижение национальных брендов, внедрение «зеленого производства», ускоренное развитие морского и железнодорожного транспорта и др. Продолжается бурное развитие китайского сектора информационных и компьютерных технологий - от мобильной телефонии и программирования до электронной торговли и всевозможных компьютерных и мобильных «приложений». Эксперты считают, что при своем огромном внутреннем рынке, быстро воспринима- 
ющем нововведения, Китай во всех этих областях может уже в ближайшее время выйти на лидирующие позиции в мире, что подстегивает и интерес европейских производителей к расширению технологического сотрудничества.

В кругах ЕС «всеобъемлющее стратегическое партнерство» с КНР в настоящее время определяется как приближающееся к стадии «зрелости». Проявление этой «зрелости» стороны усматривают и в бурном развитии сферы «человеческих контактов» (people-to-people exchanges) - широкой области, охватывающей контакты по линии образования, культуры, здравоохранения и туризма. В центре отношений такого рода находится образование. Сегодня между сторонами действует свыше 80 соглашений по сотрудничеству в образовательной области, и в Европе на сегодняшний день учатся порядка 300 тыс. китайских студентов, составляющих без малого четверть всего иностранного студенческого корпуса. В Китае обучаются 45 тыс. студентов из стран ЕС, часть из них получает китайские государственные стипендии. Сверх того, Пекин учредил в Европе 160 так называемых институтов Конфуция и почти 300 классов Конфуция [8] - культурно-образовательных центров по изучению китайского языка и культуры, сегодня образующих сеть в масштабах всего мира. Значение и масштабы взаимных туристических обменов выросли настолько, что 2018 год официально объявлен «Годом туризма между ЕС и Китаем».

Во многом взаимоотношения сторон сегодня и в самом деле представляют собой модель «зрелого» стратегического партнерства. Однако при этом в Европе, как неоднократно отмечали аналитики, объявление инициатив проекта «Один пояс - один путь» первоначально вызвало реакцию более чем «прохладную». Сотрудничая в одних областях, стороны в других сферах остаются конкурентами, и Китай в ряде европейских стран воспринимается как «вызов» и «угроза». Камнем преткновения остается проблема «китайского демпинга» - действительного или мнимого. Разногласия сторон в итоге упираются в принципиальные различия между европейской и китайской моделями экономики: в Европе, как и в иных регионах, экономику Китая не воспринимают как чисто рыночную в силу той роли, которую в КНР играют государственный сектор экономики и государственное регулирование. Наиболее болезненный для Европы вопрос - импорт китайской стали, сегодня занимающий четверть европейского сталелитейного рынка. Европейским металлургическим компаниям все труднее конкурировать с дешевой китайской сталью даже при тех антидемпинговых пошлинах, которыми ЕС пытается отгораживаться от нее. Особенно опасаются китайского демпинга и, как результат, потери рабочих мест в Южной и Восточной Европе. Со своей стороны Китай применяет антидемпинговые меры против европейских компаний. При таких противоречиях нерешенным остается вопрос о предоставлении Китаю статуса рыночной экономики в рамках ВТО, что становится серьезным 
тормозом для китайской торговой политики и в Пекине воспринимается крайне болезненно.

При всех этих противоречиях европейские элиты в последние два года демонстрируют устойчивый интерес к различным составляющим программы «Один пояс - один путь». Аналитики связывают это, прежде всего, с той тупиковой ситуацией, в которой оказались переговоры между США и ЕС по Трансатлантическому торговому и инвестиционному партнерству (ТТИП). В любом случае и независимо от хода дальнейших переговоров между Вашингтоном и Брюсселем по этому вопросу китайская программа в Европе уже сегодня воспринимается как экономически гораздо более притягательная перспектива, чем ТТИП. В отличие от американской инициативы, имеющей в виду исключительно отношения между США и ЕС и рынок емкостью 820 млн человек, «Один пояс - один путь» в перспективе может охватить свыше 65 стран и совокупный рынок почти в 4,5 млрд человек. Наконец, в Европе сегодня идет поиск стратегических путей дальнейшего развития, и этот поиск, как и китайская инициатива, ориентирован на широкомасштабные инфраструктурные проекты. В 2015 г. по так называемому Плану Юнкера здесь был создан Европейский фонд стратегических инвестиций, который, среди прочего, нацелен на широкое развитие новых транспортных магистралей как в Европе, так и за ее пределами. Аналитики уже обсуждают перспективу единой «платформы», на которой была бы возможна конвергенция «Плана Юнкера» с китайским проектом [6].

\section{ЕАЭС - Китай: \\ Проблемы и перспективы сопряжения}

Проблема реализации программы «Один пояс - один путь» применительно к Евразийскому региону очевидным образом распадается на две проблемы: во-первых, «прямых» отношений Пекина и Москвы, связанных или не связанных с последними китайскими инициативами, во-вторых, взаимоотношений КНР собственно с ЕАЭС и, шире, с государствами Центральной Азии, где два государства - Туркменистан и Узбекистан - не входят в сегодняшний Евразийский союз, но принимают то или иное участие в сотрудничестве региона с Китаем. В результате образовалась очень сложная «мозаика отношений», где за позитивной официальной риторикой всех действующих в этом случае акторов скрывается, как показывает анализ, чрезвычайно широкий и сложный комплекс интересов, устремлений и противоречий, которые в итоге и будут определять собой ход и перспективы Нового Шёлкового пути.

Кремль же еще при подготовке саммита АТЭС во Владивостоке в 2012 г. провозгласил своей стратегической задачей на XXI в. «поворот на Восток» 
с особой установкой на то, чтобы «поймать китайский ветер в паруса российской экономики». Китай сегодня воспринимается как наиболее перспективный экономический партнер России, в чем аналитики усматривают скорее новый долгосрочный проект Москвы, чем нечто, продиктованное соображениями ближайшей экономической выгоды. Однако при этом провозглашение инициатив Нового Шёлкового пути первоначально было встречено в Москве, как неизменно подчеркивалось в прессе, «без особого энтузиазма» и было воспринято как вторжение в российскую сферу влияния. Кремль, очевидно, испытывал серьезные опасения по поводу того, что с расширением присутствия Китая в Евразийском регионе «Центральная Азия уйдет». Основания для этих опасений достаточно серьезны уже по той причине, что для элит региона «быстрые инвестиции» Китая чаще всего оказываются более привлекательными, чем любые «медленные» (и, как правило, недостаточно финансируемые) проекты региональной интеграции в рамках ЕАЭС или за его пределами.

Тем не менее объявленный «поворот на Восток» должен был перейти в практическую плоскость, особенно в ситуации резкого охлаждения отношений России с Западом. В 2015 г. Москва и Пекин подписали обширный Меморандум о сотрудничестве, создав при этом Рабочую группу по отбору, оценке и реализации приоритетных проектов. В специальном соглашении стороны наметили перспективы сотрудничества «в целях практической реализации намерений о сопряжении инициатив Евразийского экономического союза и Экономического пояса Шёлкового пути» и создания в будущем единого экономического пространства и зоны свободной торговли между ЕАЭС и Китаем. Новый импульс был дан строительству магистрального газопровода «Сила Сибири», имеющего для Китая огромнейшее значение. В 2016 г. Китай, Монголия и Россия подписали ряд важных соглашений по созданию общего экономического коридора, которые эксперты оценили как настоящий прорыв по линии сопряжения имеющихся планов и инициатив. Серьезным шагом в этом направлении сегодня является участие Пекина в строительстве и техническом обеспечении первой в России высокоскоростной железнодорожной магистрали Москва - Казань с перспективой продления ее до Пекина.

При общей заинтересованности в развитии торгово-экономических отношений с Китаем России было бы крайне выгодно увеличение грузовых нагрузок на свои Транссибирскую и Байкало-Амурскую магистрали как основные транспортные коридоры для развития Сибири и Дальнего Востока. Однако сейчас транспорт грузов из Китая и других стран Восточной Азии лишь в малой степени осуществляется через эти магистрали, а основной их поток вообще оставляет Россию в стороне. Сопряжение Транссиба и БАМа с будущими маршрутами Нового Шёлкового пути могло бы, следовательно, приобрести громадное экономическое значение. Транзит китайских грузов по Транссибирской магистрали в последние годы растет ускоренными темпами, 
но по своему техническому и логистическому состоянию Транссиб сегодня не в состоянии принять на себя всю транзитную нагрузку со стороны Китая, и это вызывает в РФ серьезные опасения, что Пекин со временем будет более всего полагаться на другие - более «южные» и более современные - сухопутные маршруты своего грузового транспорта.

В стратегическом отношении решение этой и других проблем общеевразийской интеграции лежит, очевидно, на пути форсированного углубления экономического потенциала ЕАЭС и всей Центральной Азии. Со своей стороны Пекин, судя не только по официальным заявлениям, но и уже реализуемым проектам, готов к широкомасштабному сотрудничеству с евразийскими структурами. Символично, что в 2013 г. Си Цзиньпин выступил с идеей Экономического пояса Шёлкового пути именно в научном центре современного Евразийства - в Назарбаев Университете, после чего китайское руководство подписало соглашение о стратегическом партнерстве со всеми пятью центральноазиатскими республиками. Проблема в этом случае заключается в другом - насколько ЕАЭС готов к углубленному международному сотрудничеству по линии Нового Шёлкового пути. Здесь обнаруживаются свои проявления асимметрии в потенциалах и отношениях действующих акторов.

Как отмечалось выше, программа «Один пояс - один путь» не имеет какой-либо организационной структуры в том смысле, как сегодня понимается международная организация. Его критики даже говорят, что это не единый и целостный «проект», а сумма конкретных проектов, предложений и инициатив - своего рода «бренд» внешней политики Китая. Пока не вполне ясно, как эта стратегия Пекина может быть сопряжена с деятельностью ЕАЭС организации с четко определенной правовой структурой и достаточно жесткими нормами взаимодействия между государствами-членами. Скорее всего, в этом плане получат развитие разнонаправленные тенденции, конечный эффект которых сегодня непредсказуем.

С одной стороны, и это уже прослеживается на практике, Пекин, вероятно, в ближайшее время будет выстраивать свои отношения с регионом на основе двусторонних отношений с входящими в него государствами, в результате чего целостность и внутренняя солидарность Евразийского союза могут оказаться под серьезной угрозой. Уже сегодня в столицах ЕАЭС, особенно сильно в Беларуси и Казахстане, отмечается немалое разочарование относительно деятельности объединения. Россия же, «находясь под санкциями» и в ситуации падения мировых цен на нефть, имеет все меньше и меньше возможностей в плане проведения активной экономической политики в регионе. Китай же, напротив, год от года наращивает объемы своих инвестиций и кредитов в Центральную Азию. Так, Казахстан в 2016 г. получил свыше 600 млн долл. инвестиций - в 7 раз больше, чем в 2015 г., при этом общий объем накопленных китайских инвестиций в республике превысил 42 млрд долл., 
а кредитов - 50 млрд долл. [3]. В Кыргызстане объем китайских инвестиций в 2016 г. вырос более чем в 15 раз по сравнению с 2015 г. [2]. Для Таджикистана КНР сегодня является главным источником прямых иностранных инвестиций, тогда как Россия со значительным отставанием отошла на второе место.

С другой стороны, есть все основания полагать, что в долгосрочном плане Китаю было бы выгоднее решать проблемы Шёлкового пути именно с ЕАЭС как единым целым, а не с отдельными государствами Центральной Азии. В Таможенном союзе Евразийского сообщества к настоящему времени существенно упрощены таможенные процедуры, сняты внутренние таможенные границы и выработаны единые правила таможенного регулирования. Для третьих стран, в этом случае для Китая, все это означает ситуацию одного таможенного барьера вместо нескольких границ, существовавших прежде. В перспективе здесь могла образоваться огромная евразийская зона свободной торговли, где Центральная Азия (точнее, территория ЕАЭС) стала бы главным звеном. Китаю это позволило бы, например, производить продукцию в одной республике ЕАЭС и свободно продавать ее в другой - вплоть до России и Беларуси.

Реализации такого сценария сегодня мешает несколько обстоятельств, прежде всего несовпадение, а зачастую и прямой конфликт интересов центральноазиатских государств. В транспортной области, например, Кыргызстан ждет от Китая содействия в строительстве автомагистрали Север Юг Киргизии, Узбекистан стремится достраивать вместе с Пекином железную дорогу по маршруту Китай - Узбекистан - Кыргызстан, а Таджикистан опять-таки именно на Китай возлагает основные надежды на развитие своей инфраструктуры. Все это усугубляется внутрирегиональной конкурентностью в сфере контроля над трансграничными водными ресурсами (между Узбекистаном, Кыргызстаном и Таджикистаном) и борьбой за региональное лидерство (между Казахстаном и Узбекистаном).

Таким образом, в настоящее время нет весомых оснований говорить о том, что китайская стратегия Нового Шёлкового пути находится в прямой конкуренции с целями и деятельностью Евразийского сообщества. Конечно, для России в складывающейся ситуации есть определенные геополитические и геоэкономические риски, порождаемые активной экономической экспансией Пекина, но отказ Москвы от интеграционных установок и программ, на наш взгляд, чреват еще более серьезными рисками. Наблюдатели уже высказывают опасения, что строящиеся магистрали Нового Шёлкового пути пойдут в обход России, как это уже можно предполагать после недавнего введения в строй железнодорожной линии Баку - Тбилиси - Карс [5]. Пока наиболее перспективным считается маршрут, идущий в Западную Европу через Казахстан, Россию, Белоруссию и Польшу, где три из четырех стран являются 
членами ЕАЭС. Если развитие событий пойдет по этому позитивному сценарию, откроется и перспектива урегулирования отношений между РФ (вместе со всем Евразийским союзом) и Западной Европой. В треугольнике отношений ЕС - ЕАЭС - и программы «Один пояс - один путь» это на сегодняшний день наиболее проблемная сторона.

\section{EC - EAЭC:}

\section{Очертания Большой Евразии}

В 2015 г. президент Европейской комиссии Ж.К. Юнкер в письме к В.В. Путину отметил желательность установления более тесных торговых отношений между ЕС и Евразийским союзом, «которые, к сожалению, не развивались в последние годы» [12]. В действительности у ЕС изначально не было и нет никакой политики по отношению к ЕАЭС. Евразийский союз в Западной Европе воспринимается скорее как геополитический («восстановление СССР»), чем экономический проект и, следовательно, оценивается преимущественно сквозь призму отношений с Москвой, а не с ЕАЭС в целом или составляющими его государствами. При этом, как отмечают эксперты, для Европейского союза характерна своеобразная «психология исключительности». «Согласно ЕС, все европейские страны, включая Россию и другие государства постсоветского пространства, должны ориентироваться на ЕС и развивать свои отношения с ним полностью на его правовой, нормативной и политической базе... По существу, этой позиции придерживаются все европейские политики, партии и движения мейнстрима, вследствие чего России и другим членам ЕАЭС предлагается исключительно евроцентричная модель сотрудничества, модель участия в евроцентричной подсистеме международных отношений» [11].

Со стороны ЕАЭС формируется иная позиция. На Санкт-Петербургском международном экономическом форуме в 2016 г. Н.А. Назарбаев выступил с инициативой объединения ЕС и ЕАЭС и достижения своего рода «интеграции интеграций», которая серьезно приближала бы Россию и государства члены Евразийского союза к Западной Европе. Сегодня эта идея всесторонне прорабатывается. В 2016 г. Центр интеграционных исследований Евразийского банка развития - один из наиболее авторитетных на постсоветском пространстве аналитических институтов - выпустил на данную тему специальный доклад, в котором предметно рассмотрены возможные сроки и области сотрудничества двух объединений [1, с. 29]. Среди них - развитие транспортной инфраструктуры, всего того круга вопросов, которые связаны с проблематикой проекта «Один пояс - один путь». Всего выделено 20 областей, охватывающих, наряду с транспортной проблематикой, торговлю товарами, нетарифные барьеры в торговле, энергетику, защиту интеллектуальной 
собственности, миграцию, человеческие контакты и др. Авторы доклада полагают, что для полной реализации выявленных задач двум объединениям потребуется пять-семь лет. «Пока что вся проблематика, связанная с трехсторонними отношениями между ЕС, ЕАЭС и Китаем (возможно, с участием и других азиатских стран), - пишут авторы доклада, - порождает больше вопросов, чем ответов, не в последнюю очередь из-за того, что включение в уравнение китайского фактора меняет экономическое соотношение сил в Евразии» [1, с. 30]. В каком направлении будет развиваться это соотношение сил на данный момент действительно неясно, но есть довольно весомые основания думать, что при позитивных сценариях интеграционного движения в Евразии именно Евразийский союз может стать ядром новой системы экономических отношений в сегодняшнем многополярном мире.

\section{Библиография}

1. Европейский союз и Евразийский экономический союз: Долгосрочный диалог и перспективы соглашения. СПб.: ЦИИ ЕАБР, 2016. 40 с.

2. Китай в 15 раз увеличил объем инвестиций в Кыргызстан // Фергана: Информационное агентство. 2016. 9 июня. URL: https://www.fergananews.com/news/24880 (Дата обращения: 6.10.2017.)

3. Китай инвестировал в экономику Казахстана 42,8 млрд долл. за 25 лет. 8 июня 2017 г. // Акчабар. Финансовый портал [Электронный pecypc]. URL: https://www.akchabar.kg/ news/kitaj-investiroval-v-ekonomiku-kazahstana-428-mlrd-za-25-let/ (Дата обращения: 6.10.2017.)

4. Китайский Шёлковый путь принимает мировые масштабы // INOSMI. 2017. 16 мая. URL: https://www. inosmi.info/kitayskiy-shyolkovyy-put-prinimaet-mirovye-masshtaby.html (Дата обращения: 6.10.2017.)

5. «Шёлковый путь» в обход России // Euronews. 2017. 30 октября. URL: http://ru. euronews.com/2017/10/30/silk-road-but-not-in-russia (Дата обращения: 12.10.2017.)

6. Dragan P. China, the EU and One Belt, One Road Strategy. July 31, 2015 // The Jamestown [Электронный ресурс]. URL: https://jamestown.org/program/china-the-eu-and-one-belt-one-roadstrategy/ (Дата обращения: 20.10.2017.)

7. EU - China Economic Relations. 2017. June 1 // Eurostat [Электронный ресурс]. URL: http:// ec.europa.eu/eurostat/web/products-eurostat-news/-/EDN-20170601-1 (Дата обращения: 12.10.2017.)

8. EU - China Economic Relations to 2025. Building a Common Future. A Joint Report by Bruegel, Chatham House, China Center for International Economic Exchanges and the Chinese University of Hong Kong. London: Chatham House, 2017. 67 p. URL: http://bruegel.org/wp-content/uploads/ 2017/09/CHHJ5627_China_EU_Report_170913_WEB.pdf (Дата обращения: 7.11.2017.)

9. EU - China Summit: new flagship initiatives in research and innovation. Brussels, 2 June 2017 // European Commission [Электронный pecypc]. URL: http://ec.europa.eu/research/ index.cfm?pg=newsalert\&year=2017\&na=na-020617 (Дата обращения: 24.10.2017.)

10. Financing China's One Belt, One Road: US\$8 Trillion in Capital Requirements. April 3, 2017 // Silk Road Briefing [Электронный ресурс]. URL: https:/www.silkroadbriefing.com/news/ 2017/04/03/financing-chinas-one-belt-one-road-us8-trillion-in-capital-requirements/ (Дата обращения: 14.11.2017.)

11. Getting the EU and EAEU on a path to economic cooperation // Eurasian Studies: Analytical media. 2017. 20 May. URL: http://greater-europe.org/archives/2915 (Дата обращения: 9.10.2017.) 


\section{РОССИЯ И МИР В ХХІ ВЕКЕ}

12. Gotev G. Juncker opens the door to EU - Eurasian Union rapprochement // Euractiv. 2015. Nov. 20. URL: https://www.euractiv.com/section/economy-jobs/news/juncker-opens-the-door-toeu-eurasian-union-rapprochement/ (Дата обращения: 9.10.2017.)

13. Lai Suetyi. Understanding Europe's Interest in China's Belt and Road Initiative. 10 May 2017 // Carnegie Moscow center: Official Website [Электронный pecypc]. URL: http://carnegie.ru/ 2017/05/10/understanding-europe-s-interest-in-china-s-belt-and-road-initiative-pub-69920 (Дата обращения: 19.10.2017.)

\section{References}

Dragan P. China, the EU and One Belt, One Road Strategy. July 31, 2015 // The Jamestown [Jelektronnyj resurs]. URL: https://jamestown.org/program/china-the-eu-and-one-belt-one-roadstrategy/ (Data obrashhenija: 20.10.2017.)

EU - China Summit: New flagship initiatives in research and innovation. Brussels, 2 June 2017 // European Commission [Jelektronnyj resurs]. URL: http://ec.europa.eu/research/ index.cfm?pg=newsalert\&year=2017\&na=na-020617 (Data obrashenija: 24.10.2017.)

EU - China Economic Relations to 2025. Building a Common Future. A Joint Report by Bruegel, Chatham House, China Center for International Economic Exchanges and the Chinese University of Hong Kong. London: Chatham House, 2017. 67 p. URL: http://bruegel.org/wpcontent/uploads/2017/09/CHHJ5627_China_EU_Report_170913_WEB.pdf (Data obrashhenija: 7.11.2017.)

EU - China Economic Relations. 2017. June $1 / /$ Eurostat [Jelektronnyj resurs]. URL: http://ec. europa.eu/eurostat/web/products-eurostat-news/-/EDN-20170601-1 (Data obrashhenija: 12.10.2017.)

Evropejskij sojuz i Evrazijskij jekonomicheskij sojuz: Dolgosrochnyj dialog i perspektivy soglashenija. Saint-Petersburg: CII EABR, 2016. 40 p.

Financing China's One Belt, One Road: US\$8 Trillion in Capital Requirements. April 3, 2017 // Silk Road Briefing [Jelektronnyj resurs]. URL: https://www.silkroadbriefing.com/news/2017/04/03/ financing-chinas-one-belt-one-road-us8-trillion-in-capital-requirements/ (Data obrashhenija: 14.11.2017.)

Getting the EU and EAEU on a path to economic cooperation // Eurasian Studies: Analytical media. 2017. 20 May. URL: http://greater-europe.org/archives/2915 (Data obrashhenija: 9.10.2017.)

Gotev G. Juncker opens the door to EU - Eurasian Union rapprochement // Euractiv. 2015. Nov. 20. URL: https:/www.euractiv.com/section/economy-jobs/news/juncker-opens-the-door-to-eueurasian-union-rapprochement/ (Data obrashhenija: 9.10.2017.)

Kitaj investiroval v jekonomiku Kazahstana \$42,8 mlrd za 25 let. 8 ijunja 2017 g. // Akchabar. Finansovyj portal [Jelektronnyj resurs]. URL: https://www.akchabar.kg/news/kitaj-investiroval-vekonomiku-kazahstana-428-mlrd-za-25-let/ (Data obrashhenija: 6.10.2017.)

Kitaj v 15 raz uvelichil ob'em investicij v Kyrgyzstan // Fergana: Informacionnoe agentstvo. 2016. June 9. URL: https://www.fergananews.com/news/24880 (Data obrashhenija: 6.10.2017.)

Kitajskij Shjolkovyj put' prinimaet mirovye masshtaby // INOSMI. 2017. May 16. URL: https://www.inosmi.info/kitayskiy-shyolkovyy-put-prinimaet-mirovye-masshtaby.html (Data obrashhenija: 6.10 .2017$.

Lai Suetyi. Understanding Europe's Interest in China's Belt and Road Initiative. 10 May $2017 / /$ Carnegie Moscow center: Official Website [Jelektronnyj resurs]. URL: http://carnegie.ru/2017/05/10/ understanding-europe-s-interest-in-china-s-belt-and-road-initiative-pub-69920 (Data obrashhenija: 19.10.2017.)

«Shelkovyj put'» v obhod Rossii // Euronews. 2017. Oct. 30. URL: http://ru.euronews.com/ 2017/10/30/silk-road-but-not-in-russia (Data obrashhenija: 12.10.2017). 